\title{
Comparison of the nuclear data libraries in the shielding calculation for the accelerator facility of the Proton Engineering Frontier Project in Korea
}

\author{
C.W. Lee, Y.O. Lee, and Y.S. Cho \\ Korea Atomic Energy Research Institute, Daejeon, Korea
}

\begin{abstract}
The radiation shielding calculations were performed for the beam experiment hall of the Proton Engineering Frontier Project (PEFP) in Korea using MCNPX code with nuclear data libraries of the ENDF-B/VII, JEFF3.1, LA150, JENDL-HE, and physics models, Bertini and Isabel built in MCNPX code. The neutron energy spectra from 6 targets $(20 \mathrm{MeV} / 1.5 \mathrm{~mA}-\mathrm{Si}, \mathrm{Cu}$, target, $20 \mathrm{MeV} / 50 \mathrm{uA}-\mathrm{Si}, 20 \mathrm{MeV} / 4.8 \mathrm{~mA}-\mathrm{C}$ target, $100 \mathrm{MeV} /$ $300 \mathrm{uA}-\mathrm{Si}$, W target, $100 \mathrm{MeV} / 10 \mathrm{uA}-\mathrm{Si}, 100 \mathrm{MeV} / 1.6 \mathrm{~mA}-\mathrm{C}$ target) were calculated and used as radiation source terms. With these results, the concrete thickness satisfying shielding regulations in Korea was calculated for the target rooms and the building of the Beam Experiment Hall. Bertini, Isabel, JENDL/HE and LA150 nuclear data were applied to the evaluation of the proton induced neutrons. ENDF/B-VII, JEFF3.1, and JENDL/HE nuclear data were applied to the evaluation of the concrete shield.
\end{abstract}

\section{Introduction}

A transport method or physics, realization of the geometrical model, and nuclear data are important factors which decide the accuracy of the radiation transport. Of these, transport method or physics should be decided when the radiation transport code or methods is selected and a geometrical model has the limit of a description. Therefore, a selection of the nuclear data which will be used in the simulation is very important for the reliance of the radiation transport simulation. There are many nuclear data available in the radiation transport simulation [1].

In this paper, ENDF/B-VII, JENDL/HE, and JEFF3.1 were compared in the aspect of the radiation shielding calculation. The physics models such as Bertini and Isabel were additionally considered. MCNPX 2.5 code [2] using Monte Carlo Method was used in this study to compare nuclear data. A beam experiment hall in the proton accelerator facility with 2 MW under Proton Engineering Frontier Project (PEFP) in Korea was considered as a simulation model.

\section{Benchmark calculation with MCNPX code}

The neutron source term and shielding effect of concrete are mainly considered in the accelerator shielding calculation. From these reasons, neutron production rate from the various targets and depth dose in the concrete wall were evaluated with various nuclear data and physics models.

\subsection{Calculation of the neutron production rate from targets}

Since protons have generally very short mean free path in the materials, neutrons produced from the proton-induced reaction are main radiation source in a proton accelerator. In this study, neutron production rate from targets in the beam experiment hall of the proton accelerator facility of PEFP were evaluated and compared using various nuclear data. In the accelerator facility of PEFP, $\mathrm{Ag}, \mathrm{C}, \mathrm{Si}$, and $\mathrm{W}$ are being considered as a target material for the $100 \mathrm{MeV}$ proton beam. For the $20 \mathrm{MeV}$ proton beam, $\mathrm{Be}, \mathrm{Cu}, \mathrm{Si}$, and $\mathrm{C}$ are being considered as a target material [3].

Nuclear data, LA150 and JENDL/HE, and physics model, Bertini and Isabel, were applied for evaluating the neutron production rate from those targets. Targets used in this calculation are shown in table 1. Because JENDL/HE and LA150 libraries do not include the cross section of the proton induced reactions for $\mathrm{Ag}$ and $\mathrm{Be}$, "Ag target" for $100 \mathrm{MeV}$ proton beam and "Be target" for $20 \mathrm{MeV}$ proton beam were not considered in this calculation.

Among isotopes in the target materials, ${ }^{13} \mathrm{C}$ and ${ }^{180} \mathrm{~W}$ is not included in the LA150 library. JENDL/HE library includes ${ }^{13} \mathrm{C}(\mathrm{p}, \mathrm{n}){ }^{13} \mathrm{~N}$ reaction which has the $\mathrm{Q}$-value, $-3.003 \mathrm{MeV}$. This is the main reason for the large difference of the neutron production rate between JENDL/HE and LA150 library for the proton beam of $20 \mathrm{MeV}$.

Bertini physics model shows the largest neutron production rate than nuclear data and Isabel model for $\mathrm{C}$ and $\mathrm{Si}$ target using a proton beam of $100 \mathrm{MeV}$. JENDL/HE shows the largest neutron production rate than nuclear data and Isabel model for $\mathrm{C}$ and $\mathrm{Si}$ target using a proton beam of $20 \mathrm{MeV}$ and $\mathrm{W}$ target using a proton beam of $100 \mathrm{MeV}$.

In the low neutron energy range below hundreds of kiloelectron volt (keV), JENDL/HE library has the highest neutron production rate for all targets considered in this calculation. In the energy range from 1 to $20 \mathrm{MeV}$, LA150 has the highest neutron production rate than other nuclear data libraries and physics model. In the high energy region over $20 \mathrm{MeV}$, Isabel physics model has highest neutron production rate.

Between JENDL/HE and LA150, JENDL/He library shows higher total neutron production rate than LA150 generally. But, LA150 shows higher neutron production rate than JENDLE/HE for C target.

The total neutron production rates are shown in table 2 . And energy spectra of the neutrons produced from targets are shown in figures 1 through 5 . 
Table 1. Targets in the beam experiment hall in the accelerator facility of PEFP.

\begin{tabular}{cccc}
\hline Target & $\begin{array}{c}\text { Density } \\
{\left[\mathrm{g} / \mathrm{cm}^{3}\right]}\end{array}$ & Isotope & $\begin{array}{c}\text { Atomic density } \\
{\left[\# / \mathrm{b} \cdot \mathrm{cm}^{3}\right]}\end{array}$ \\
\hline $\mathrm{C}$ & 2.250 & ${ }^{12} \mathrm{C}$ & $1.1156 \times 10^{-1}$ \\
& & ${ }^{13} \mathrm{C}$ & $1.2522 \times 10^{-3}$ \\
\hline $\mathrm{Si}$ & 2.329 & ${ }^{28} \mathrm{Si}$ & $4.6057 \times 10^{-2}$ \\
& & ${ }^{29} \mathrm{Si}$ & $2.3321 \times 10^{-3}$ \\
& & ${ }^{30} \mathrm{Si}$ & $1.5481 \times 10^{-3}$ \\
\hline $\mathrm{W}$ & 19.300 & ${ }^{180} \mathrm{~W}$ & $7.5865 \times 10^{-5}$ \\
& & ${ }^{182} \mathrm{~W}$ & $1.6752 \times 10^{-2}$ \\
& & ${ }^{183} \mathrm{~W}$ & $9.0494 \times 10^{-3}$ \\
& & ${ }^{184} \mathrm{~W}$ & $1.9372 \times 10^{-2}$ \\
& & ${ }^{186} \mathrm{~W}$ & $1.7971 \times 10^{-2}$ \\
\hline $\mathrm{Cu}$ & 8.960 & ${ }^{63} \mathrm{Cu}$ & $5.8732 \times 10^{-2}$ \\
& & ${ }^{65} \mathrm{Cu}$ & $2.6178 \times 10^{-2}$ \\
\hline
\end{tabular}

Table 2. Neutron production rate from targets in the beam experiment hall in the accelerator facility of PEFP.

\begin{tabular}{ccccc}
\hline \multirow{2}{*}{ Target } & \multicolumn{4}{c}{ Neutron production rate [\#/proton] } \\
\cline { 2 - 5 } & Bertini & Isabel & JENDL/HE & LA150 \\
\hline \multicolumn{5}{c}{$100 \mathrm{MeV}$ proton beam } \\
\hline $\mathrm{C}$ & 0.0198 & 0.0178 & 0.0166 & 0.0181 \\
$\mathrm{Si}$ & 0.0239 & 0.0211 & 0.0236 & 0.0203 \\
$\mathrm{~W}$ & 0.3891 & 0.3577 & 0.4207 & 0.3258 \\
\hline \multicolumn{5}{c}{$20 \mathrm{MeV}$ proton beam } \\
\hline $\mathrm{C}$ & $8.4 \times 10^{-5}$ & $7.6 \times 10^{-5}$ & $6.1 \times 10^{-5}$ & $8.0 \times 10^{-5}$ \\
$\mathrm{Cu}$ & 0.0053 & 0.00502 & 0.00879 & 0.00449 \\
\hline \multicolumn{5}{c}{}
\end{tabular}

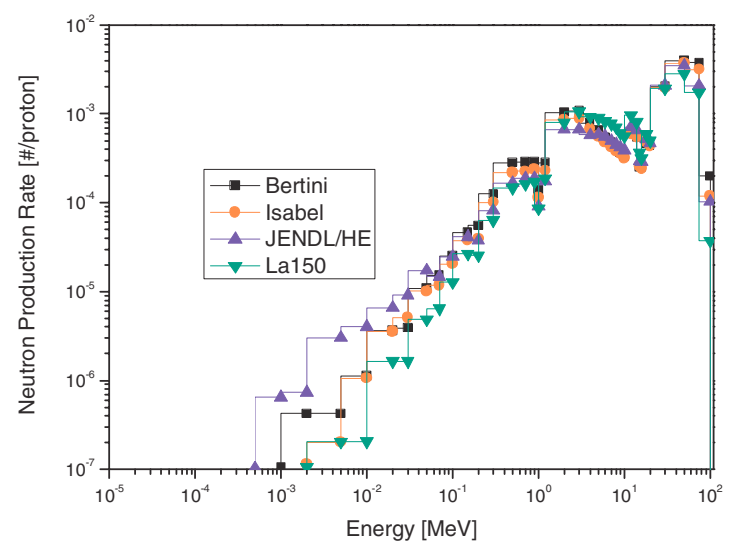

Fig. 1. Neutron spectra from the $\mathrm{C}$ target for $100 \mathrm{MeV}$ proton beam.

\subsection{Depth dose rate in the concrete wall}

In the aspect of the radiation shielding for an accelerator facility, depth dose in the concrete wall were calculated with ENDF/B-VII, JEFF3.1, and JENDL/HE libraries.

Composition of the concrete used in this calculation is shown in table 3 . Two neutron spectra from $\mathrm{W}$ target for proton beam of $100 \mathrm{MeV}$ and $\mathrm{C}$ target for the proton beam of $20 \mathrm{MeV}$ were applied to the depth dose calculation in concrete wall.

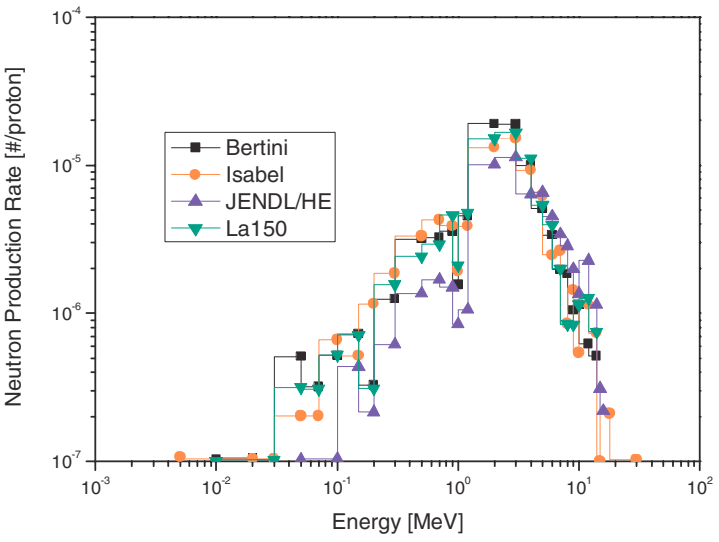

Fig. 2. Neutron spectra from the $\mathrm{C}$ target for $20 \mathrm{MeV}$ proton beam.

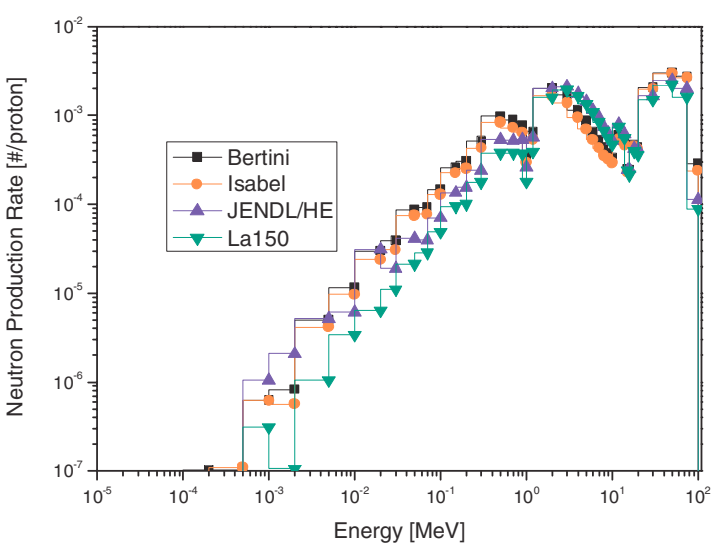

Fig. 3. Neutron spectra from the Si target for $100 \mathrm{MeV}$ proton beam.

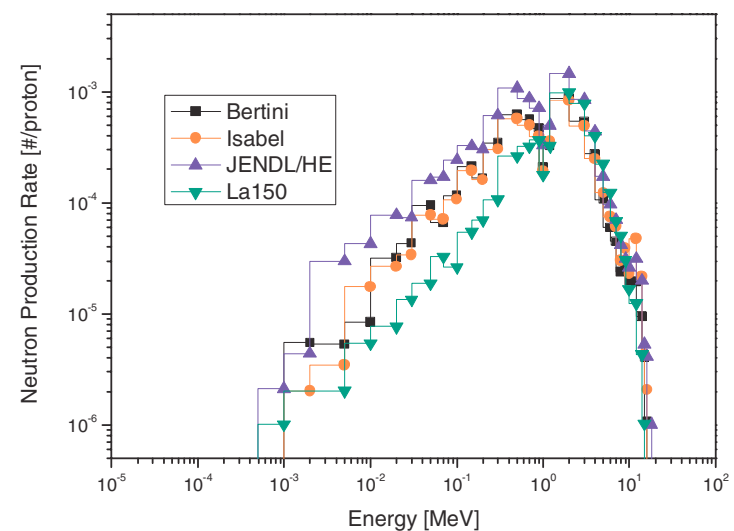

Fig. 4. Neutron spectra from the $\mathrm{Cu}$ target for $20 \mathrm{MeV}$ proton beam.

ICRP-74 dose conversion factor was used in the neutron dose evaluation.

JEFF3.1 underestimated the neutron dose with a difference of $9 \%$ than other nuclear data library in the concrete thickness over $70 \mathrm{~cm}$ for a $20 \mathrm{MeV}$ proton beam. In the shielding calculation which transports neutrons through thick concrete wall, the results from figures 6 and 7 show that the difference due to nuclear data is not significant for ENDF/B-VII and JENDL/HE. 


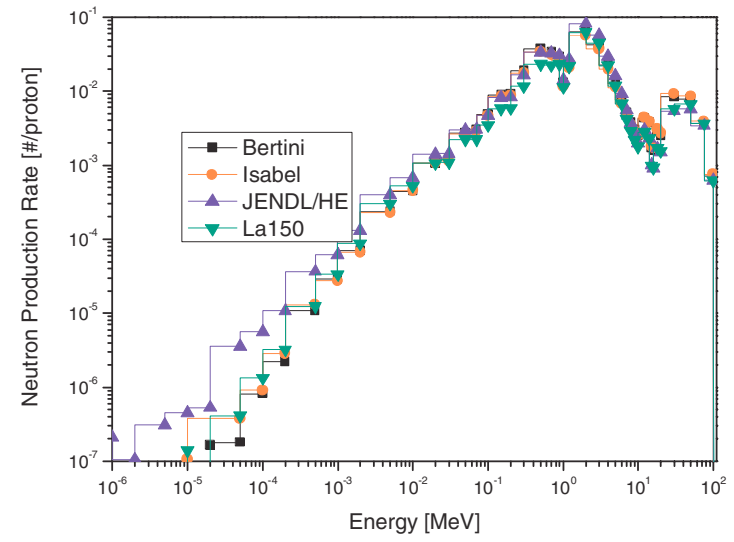

Fig. 5. Neutron spectra from the $\mathrm{W}$ target for $100 \mathrm{MeV}$ proton beam.

Table 3. Material composition of concrete (density $\rho=$ $2.2428 \mathrm{~g} / \mathrm{cm}^{3}$ ).

\begin{tabular}{|c|c|c|c|}
\hline Atom & $\begin{array}{c}\text { Fraction } \\
\text { [weight \%] }\end{array}$ & Isotope & $\begin{array}{l}\text { Atomic density } \\
\qquad\left[\# / \mathrm{b} \cdot \mathrm{cm}^{3}\right]\end{array}$ \\
\hline $\mathrm{H}$ & 0.100 & $\begin{array}{l}{ }^{1} \mathrm{H} \\
{ }^{2} \mathrm{H}\end{array}$ & $\begin{array}{l}1.3398 \times 10^{-2} \\
2.0100 \times 10^{-6}\end{array}$ \\
\hline $\mathrm{C}$ & 0.001 & $\begin{array}{l}{ }^{12} \mathrm{C} \\
{ }^{13} \mathrm{C} \\
\end{array}$ & $\begin{array}{l}1.1120 \times 10^{-4} \\
1.2482 \times 10^{-6} \\
\end{array}$ \\
\hline $\mathrm{O}$ & 0.529 & $\begin{array}{l}{ }^{16} \mathrm{O} \\
{ }^{17} \mathrm{O} \\
{ }^{18} \mathrm{O} \\
\end{array}$ & $\begin{array}{l}4.4559 \times 10^{-2} \\
1.6973 \times 10^{-5} \\
8.9331 \times 10^{-5} \\
\end{array}$ \\
\hline $\mathrm{Na}$ & 0.016 & ${ }^{23} \mathrm{Na}$ & $9.3997 \times 10^{-4}$ \\
\hline $\mathrm{Mg}$ & 0.002 & $\begin{array}{l}{ }^{24} \mathrm{Mg} \\
{ }^{25} \mathrm{Mg} \\
{ }^{26} \mathrm{Mg}\end{array}$ & $\begin{array}{l}8.7789 \times 10^{-5} \\
1.1114 \times 10^{-5} \\
1.2236 \times 10^{-5} \\
\end{array}$ \\
\hline $\mathrm{Al}$ & 0.034 & ${ }^{27} \mathrm{Al}$ & $1.6955 \times 10^{-3}$ \\
\hline $\mathrm{Si}$ & 0.337 & $\begin{array}{l}{ }^{28} \mathrm{Si} \\
{ }^{29} \mathrm{Si} \\
{ }^{30} \mathrm{Si} \\
\end{array}$ & $\begin{array}{l}1.4948 \times 10^{-2} \\
7.5687 \times 10^{-4} \\
5.0242 \times 10^{-4} \\
\end{array}$ \\
\hline $\mathrm{K}$ & 0.013 & $\begin{array}{l}{ }^{39} \mathrm{~K} \\
{ }^{40} \mathrm{~K} \\
{ }^{41} \mathrm{~K} \\
\end{array}$ & $\begin{array}{l}.1880 \times 10^{-4} \\
5.2542 \times 10^{-8} \\
3.0223 \times 10^{-5}\end{array}$ \\
\hline $\mathrm{Ca}$ & 0.044 & $\begin{array}{l}{ }^{40} \mathrm{Ca} \\
{ }^{42} \mathrm{Ca} \\
{ }^{43} \mathrm{Ca} \\
{ }^{44} \mathrm{Ca} \\
{ }^{46} \mathrm{Ca} \\
{ }^{48} \mathrm{Ca}\end{array}$ & $\begin{array}{l}1.4374 \times 10^{-3} \\
9.5936 \times 10^{-6} \\
2.0018 \times 10^{-6} \\
3.0931 \times 10^{-5} \\
5.9311 \times 10^{-8} \\
2.7728 \times 10^{-6}\end{array}$ \\
\hline $\mathrm{Fe}$ & 0.014 & $\begin{array}{l}{ }^{54} \mathrm{Fe} \\
{ }^{56} \mathrm{Fe} \\
{ }^{57} \mathrm{Fe} \\
{ }^{58} \mathrm{Fe}\end{array}$ & $\begin{array}{l}8.6669 \times 10^{-5} \\
1.3605 \times 10^{-3} \\
3.1420 \times 10^{-5} \\
4.1815 \times 10^{-6}\end{array}$ \\
\hline
\end{tabular}

\section{Conclusion}

A comparison of the nuclear data libraries and physics models in the shielding calculations for the accelerator facility of

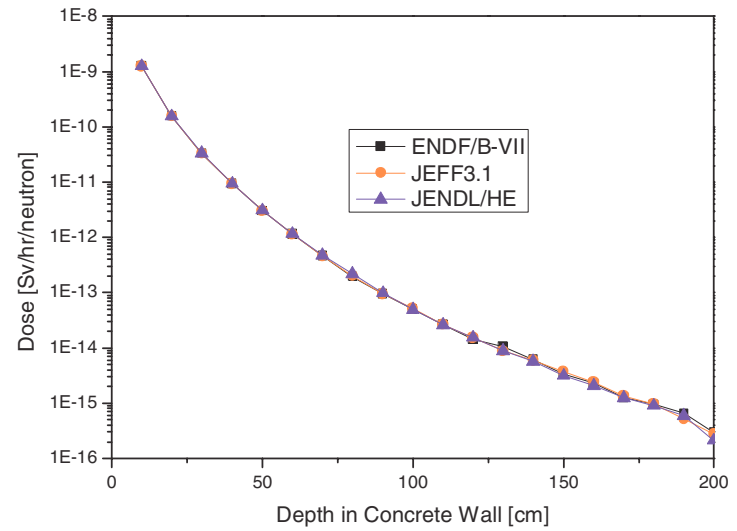

Fig. 6. Dose distribution in the concrete shield with the neutron source from the $\mathrm{W}$ target for $100 \mathrm{MeV}$ proton (neutron source was calculated with JENDL/HE library by using MCNPX code).

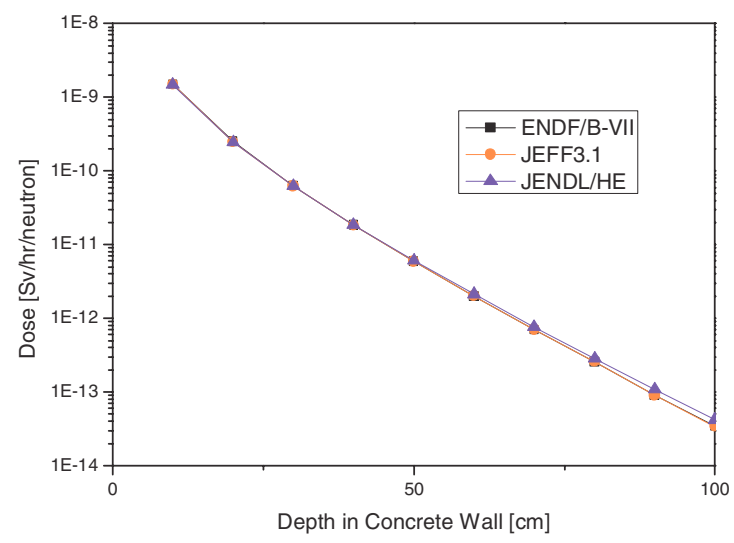

Fig. 7. Dose distribution in the concrete shield with the neutron source from the Be target for $20 \mathrm{MeV}$ proton (neutron source was calculated with Bertini Model by using MCNPX code).

PEFP in Korea was performed. For the W, C, Cu and Si, target, neutron production rate from the proton induced reaction were calculated with JENDL/HE and LA150 libraries as well as Bertini and Isabel physics model. The difference of the neutron dose in the concrete wall was examined with ENDF/B-VII, JEFF3.1, and JENDL/HE libraries.

In a shielding calculation for a large scale, nuclear data should be considered for radiation source term evaluation. After evaluations of the source term, the difference due to nuclear data used in neutron transport, like dose calculations, in the facility is not significant.

\section{References}

1. A.J. Koning, J.P. Delaroche, O. Bersillon, Nucl. Instrum. Meth. Phys. Res. A 414, 49 (1998).

2. D.B. Pelowitz et al., BMCNPX User's Manual version 2.5.0., LA-CP-05-0369, LANL, 2005.

3. KAERI, Internal Materials. 